\title{
ASO Author Reflections: Impact of Surgical Methods on Long- Term Survival Outcomes for Patients with Duodenal Gastrointestinal Stromal Tumor
}

\author{
You-Zhu Wei, MD ${ }^{1}$, and Yan-Ming Zhou, $\mathrm{MD}^{1,2}$ \\ ${ }^{1}$ Xiamen Humanity Hospital, Fujian Medical University, Xiamen, China; ${ }^{2}$ Department of Surgery, First Affiliated Hospital \\ of Xiamen University, Xiamen, China
}

\section{PAST}

Duodenal gastrointestinal stromal tumor (GIST) represents a rare subset of GIST arising in the gastrointestinal tract. Surgical resection of duodenal GIST is particularly challenging due to the anatomic complexity of its location in close proximity to the head of the pancreas, bile duct, and mesenteric vessels. Surgical management of duodenal GIST varies from radical resection (RR), such as pancreaticoduodenectomy (PD), to limited resection (LR) including segmental duodenectomy or wedge resection, but few studies have reported investigations showing which of the two surgical strategies is the most beneficial to longterm patient survival. ${ }^{1-4}$

\section{PRESENT}

In the current study, ${ }^{5} 105$ patients $(32.3 \%)$ underwent $\mathrm{RR}$, and 220 patients $(67.7 \%)$ received LR. The survival outcomes in the RR group were significantly better than those in the LR group. Propensity score-matching resulted in 95 pairs of patients, with long-term outcomes comparable between the two groups. After adjustment for covariates in the propensity-matched cohort, the type of surgery still showed no significant impact on survival.

\section{FUTURE}

The type of surgery does not seem to have a significant impact on the long-term survival outcome for patients with duodenal GIST and therefore should depend primarily on tumor location and size.

DISCLOSURE There are no conflict of interest.

\section{REFERENCES}

1. Colombo C, Ronellenfitsch U, Yuxin Z, et al. Clinical, pathological, and surgical characteristics of duodenal gastrointestinal stromal tumor and their influence on survival: a multi-center study. Ann Surg Oncol. 2012;19:3361-7. https://doi.org/10.1245/ s10434-012-2559-0.

2. Johnston FM, Kneuertz PJ, Cameron JL, et al. Presentation and management of gastrointestinal stromal tumors of the duodenum: a multi-institutional analysis. Ann Surg Oncol. 2012;19:3351-60. h ttps://doi.org/10.1245/s10434-012-2551-8.

3. Zhang Q, Shou CH, Yu JR, et al. Prognostic characteristics of duodenal gastrointestinal stromal tumours. $\mathrm{Br} \quad \mathrm{J}$ Surg. 2015;102:959-64. https://doi.org/10.1002/bjs.9831.

4. Lee SY, Goh BK, Sadot E, et al. Surgical strategy and outcomes in duodenal gastrointestinal stromal tumor. Ann Surg Oncol. 2017;24:202-10. https://doi.org/10.1245/s10434-016-5565-9.

5. Wei YZ, Cai ZB, Zhu CL, Zhou YM, Zhang XF. Impact of surgical modalities on long-term survival outcomes of patients with duodenal gastrointestinal stromal tumor. Ann Surg Oncol. 2021. https://doi.org/10.1245/s10434-020-09497-0.

Publisher's Note Springer Nature remains neutral with regard to jurisdictional claims in published maps and institutional affiliations.

(C) Society of Surgical Oncology 2021

First Received: 4 December 2020

Accepted: 4 December 2020;

Published Online: 17 January 2021

Y.-M. Zhou, MD

e-mail: zhouymsxy@sina.cn 